\title{
Necessidade de confiança na jurisdição constitucional para efetivação do direito à saúde
}

\author{
Confidence in need jurisdiction constitutional right to health of effective \\ Nécessité de la confiance dans la juridiction constitutionnelle pour la \\ réalisation du droit à la santé
}

\section{Necesidad de confianza en la jursidición constitucional para la efectividad del derecho a la salud}

\author{
Sandra Regina Martini ${ }^{1}$ \\ André Santos Chaves ${ }^{2}$
}

Recebido em 07/06/2017; revisado e aprovado em 18/07/2017; aceito em 25/07/2017

DOI: http://dx.doi.org/10.20435/inter.v19i1.1626

\begin{abstract}
Resumo: A judicialização da política em saúde trouxe o debate, no seio do sistema jurídico, a respeito da efetivação do direito à saúde previsto na Constituição. Como fazer que uma decisão judicial seja compreendida como um direito e como um valor pelo sistema do direito e pelo sistema da política, respectivamente, será compreender que essa decisão judicial precisa ser proferida pelo Supremo Tribunal Federal como organização centralizadora ou de centro do sistema do direito, e essa compreensão será dada por meio do instituto da repercussão geral como mudança da estrutura do sistema do direito para garantir aquisição evolutiva do sistema jurídico.
\end{abstract}

Palavras-chave: teoria dos sistemas; confiança; tribunais; saúde; Constituição.

Abstract: The judicialization of health policy has brought the debate within the legal system concerning the realization of the right to health in the Constitution. How to make a judgment to be understood as a right and as a value for the right system and the political system, respectively, will understand that this judicial decision must be handed down by the Supreme Court as a centralized organization or legal system center and this understanding will be given through the institute of general repercussion as change of law system structure to ensure evolutionary acquisition of the legal system.

Keywords: systems theory; confidence; courts; health; Constitution.

Résumé: La judiciarisation de la politique de santé a amené le débat, au sein du système juridique, sur la réalisation du droit à la santé prévu dans la Constitution. Comment faire une décision judiciaire comprise comme un droit et comme une valeur par le système de droit et par le système politique, respectivement, sera de comprendre que cette décision judiciaire doit être rendue par la Cour suprême fédérale en tant qu'organisation centralisatrice ou centre du système juridique, et cette compréhension sera donnée à travers l'institut de répercussion générale comme un changement dans la structure du système juridique pour assurer l'acquisition évolutive du système juridique.

Motes-clé: théorie des systèmes; la confiance; tribunaux; santé Constitution.

Resumen: La judicialización de la política en salud trajo el debate, en el seno del sistema jurídico, acerca de la efectividad del derecho a la salud previsto en la Constitución. ¿Cómo hacer que una decisión judicial sea comprendida como un derecho y como un valor por el sistema del derecho y por el sistema de la política, respectivamente, será comprender que esta decisión judicial debe ser dictada por el Supremo Tribunal Federal como organización centralizadora o de centro del sistema del derecho Y esta comprensión se dará por medio del instituto de la repercusión general como cambio de la estructura del sistema del derecho para garantizar la adquisición evolutiva del sistema jurídico.

Palabras clave: teoría de los sistemas; confianza; tribunales; salud; Constitución.

\footnotetext{
${ }^{1}$ Centro Universitário Ritter dos Reis (UniRitter), Porto Alegre, Rio Grande do Sul, Brasil.

${ }^{2}$ Universidade do Vale do Rio dos Sinos (UNISINOS), São Leopoldo, Rio Grande do Sul, Brasil.
} 


\section{INTRODUÇÃO}

A promulgação da Constituição de 1988 foi um marco no tocante à saúde, uma vez que a sociedade brasileira, a partir de cinco de outubro daquele ano, optou por incluir, como um direito de todos, o direito à saúde. A inclusão desse direito evidenciou a existência de uma parcela significativa da população sem o gozo de "saúde", entendida como o mais completo bem-estar, e também evidenciou a necessidade de o sistema político, representado pelo Estado brasileiro, efetivar políticas públicas que pudessem efetivar o direito à saúde e os princípios contidos nos artigos 60 e 196, ambos da Constituição.

Todavia a realidade da sociedade brasileira mostrou que a implementação de políticas públicas relativas à positivação dos novos direitos na Constituição esbarravam em questões orçamentárias, ou seja, havia a previsão legal, porém não eram efetivados ou operacionalizados pelo sistema da política, sob a alegação de ausência de verba necessária para devida implementação.

Junto com a positivação do direito na Constitiução, surgiu para o Poder Judiciário, quando acionado, necessidade de julgamento e prolação de uma decisão com intuito de garantir ao jurisdicionado o gozo de seu direito à saúde. Por meio de organizações do Poder Judiciário, principalmente, a Defensoria Pública, assistiu-se a um aumento expressivo do número de ajuizamento de ações judiciais cobrando dos entes federados (União, Estados-membro, Municípios e o Distrito Federal) o cumprimento da Constituição e o cumprimento e efetivação do direito à saúde, que pode ser traduzido na efetivação de políticas públicas, na compra de medicamentos, na exigência de intervenções cirúrgicas etc. Esse fenômeno foi denominado de judicialização da política ou judicialização da saúde e trouxe o debate acerca da possibilidade de o Poder Judiciário efetivar o direito à saúde por meio de decisões judiciais que ordenassem o cumprimento de políticas púbicas, exemplificativamente.

O que se assistiu inicialmente com o ajuizamento de ações contra o Poder Público exigindo o cumprimento do direito à saúde do jurisdicionado foi uma massiva quantidade de decisões proferidas pelos juízes (de primeiro grau) e tribunais (de apelação) com a consequente repercussão no sistema da política. Foram decisões judiciais ordenando que o Poder Executivo cumprisse uma política pública de vacinação, de fornecimento de medicamentos não previstos na listagem do SUS (RENAME), de intervenção cirúrgica para casos urgentes, de sequestro de verbas públicas para aquisição de fármacos, enfim foram decisões judiciais que tiveram a capacidade de interferir, de impor perigo ao sistema da política, tendo o sistema da política, em muitos casos, absorvido as decisões judiciais e transformando-as em risco.

Não obstante a garantia constitucional de livre acesso ao Poder Judiciário, o que se observou é que o expressivo número de ações judiciais cujo pedido era de cumprimento do direito à saúde, o sistema do direito não conseguia diminuir a complexidade do entorno, na medida que as decisões judiciais proferidas pelos juízes (de primeiro grau) e pelos tribunais (de apelação) não eram passíveis de generalização e aplicação em casos semelhantes, o que acabou prejudicando a confiança e a racionalidade do sistema do direito.

Neste artigo, a intenção é analisar a evolução das estruturas do sistema do direito que permitiram o retorno da confiança (como categoria sistêmica), da racionalidade e da centralidade do Supremo Tribunal Federal no tocante à aplicação do direito à saúde.

Estruturas foram alteradas ou criadas que permitiram que o sistema do direito absorvesse a complexidade do entorno e mantivesse a sua autopoiese de maneira que os códigos do sistema 
do direito e do sistema da política continuassem hígidos, ou seja, o sistema do direito evoluiu para continuar decidindo de maneira autopoiética (código direito/não-direito) e o sistema da política igualmente evoluiu e, mesmo irritado, absorveu o risco provocado pelo sistema do direito com o código que também Ihe é próprio (governo/oposição), ou seja, as decisões judiciais continuaram a ser consideradas decisões jurídicas, e as decisões políticas continuaram a ser consideradas decisões tomadas de maneira coletivamente vinculantes.

Para este estudo, a teoria sistêmica, de matriz luhmaniana é apropriada para captar a complexidade do entorno, a mudança das estruturas do sistema do direito e a maneira como a autopoiese será mantida, uma vez que cada sistema manterá seu fechamento operativo e sua abertura cognitiva.

Para esta seara, optou-se por trabalhar a Constituição como uma aquisição evolutiva (item 2), a inexistência ou a dificuldade, antes da Constituição de 1988, do sistema do direito em operacionalizar a positivação dos novos direitos sociais plasmados na Constituição (item 3), a criação do instituto da repercussão geral como fenômeno da auto-observação do sistema do direito (item 4), o instituto da repercussão geral como mudança estrutural do sistema do direito que devolveu o papel centralizador ou central do Supremo Tribunal Federal (item 5) e, por fim, no item 6, a evolução do sistema do direito no tocante à efetivação do direito à saúde pelo Supremo Tribunal Federal por meio do instituto da repercussão geral.

\section{A CONSTITUIÇÃO COMO AQUISIÇÃO EVOLUTIVA ENTRE OS SISTEMAS DO DIREITO E DA POLÍTICA}

A atual complexidade da sociedade faz com que seja necessária a existência de sistemas sociais, ou subsistemas sociais, capazes de absorver a complexidade por meio de um código próprio (fechamento operativo). Não obstante os sistemas serem fechados operativamente, há necessidade de que se mantenham abertos (abertura cognitiva) por meio de estruturas que permitam que o "ruído do entorno" (complexidade) seja absorvido com o código próprio de cada sistema, essas estruturas são responsáveis por manter os sistemas sociais em constante deriva estrutural, nas palavras de Maturana e Varela (2011), ou seja, ligados, porém separados.

A Constituição é a estrutura que permite conectar e separar os sistemas do direito e da política, uma vez que é considerada uma aquisição evolutiva (LUHMANN, 1990) da modernidade atual.

Basta imaginar que nem sempre foi assim. O julgamento dos conflitos envolvendo os súditos, durante a Idade Média e Moderna, era uma função do rei ${ }^{3}$, do soberano. As desavenças

\footnotetext{
${ }^{3}$ A justiça, o Poder Judiciário, o Sistema do Direito, era, inicialmente, uma função do que hoje se denomina Poder Executivo. Foi a evolução da sociedade que criou a necessidade de distinção entre a função de julgar e a função de governar. ("Há, em cada Estado, três espécies de poderes: o poder legislativo, o poder executivo das coisas que dependem do direito das gentes, e o executivo das que dependem do direito civil.

Pelo primeiro, o príncipe ou magistrado faz leis por certo tempo ou para sempre e corrige ou ab-roga as que estão feitas. Pelo segundo, faz a paz ou a guerra, envia ou recebe embaixadas, estabelece a segurança, previne as invasões. Pelo terceiro, pune os crimes ou julga as querelas dos indivíduos. Chamaremos este último o poder de julgar e o outro, simplesmente o poder executivo do Estado" (MONTESQUIEU, 1997, p. 201). Aliás, a noção de que o Poder Judiciário é uma função do Poder Executivo, no sentido de "executar" a lei criada pelo Poder Legislativo também se encontra em Locke quando afirma "Os que estão unidos em um corpo, tendo lei comum estabelecida e judicatura - para a qual apelar - com autoridade para decidir controvérsias e punir os ofensores, estão em sociedade civil uns com os outros; [...] E aqui deparamos com a origem dos poderes legislativo e executivo da sociedade, que deve julgar por meio de leis estabelecidas até que pondo se devem castigar as ofensas quando cometidas dentro dos
} 
eram levadas ao rei, que, então, era encarregado de distribuir justiça julgando os casos de acordo com as normas e costumes da época. Ocorre que a quantidade de demandas, a quantidade de conflitos envolvendo os súditos foi crescendo ao longo dos anos, fazendo com que, nas vésperas da Revolução Francesa, já existisse, em diversos países, um corpo de funcionários encarregados de aplicar a justiça em nome do rei. Foi necessário, portanto, para se poder distinguir o que seria uma decisão do rei em relação a questões envolvendo "governar" e decisão do rei envolvendo "julgar", uma vez que ambas eram decisões proferidas pelo rei.

Os tribunais surgem, nesse contexto, como uma diferenciação ${ }^{4}$ necessária a ponto de garantir um procedimento diferente para se tomar decisões judiciais e um procedimento diferente para se tomar decisões não judiciais. A possibilidade de o derrotado poder questionar a decisão do funcionário do rei perante outra instância tem o condão de incluir, no âmbito do sistema do direito, o risco de tornar a decisão judicial contingente. Essa evolução foi necessária para se conseguir visualizar uma distinção entre o sistema da política e o sistema do direito: a decisão política esgota-se numa decisão do soberano, numa decisão de quem possui poder e seguindo-se um procedimento legislativo, enquanto a decisão judicial esgota-se quando uma das partes conforma-se com a decisão judicial proferida pelo juiz ou quando suporta o fato de haver uma última instância de julgamento em determinado momento do processo. Criada, portanto, uma diferenciação interna no âmbito do sistema do direito: hierarquização por meio dos tribunais, sendo possível separar o sistema da política e o sistema do direito.

A ideia da separação dos poderes é suficiente para compreender que havia limites, na nascente sociedade industrial (pós revolução francesa) entre o sistema da política e o sistema do direito, não existindo uma estrutura capaz de conectá-los (acoplamento estrutural) e por isso o sucesso da ideia de Montesquieu, adequada a uma sociedade ainda pouco complexa.

Todavia, as mudanças sociais (aumento da complexidade) ocorridas com a industrialização da sociedade provocaram evolução nos sistemas do direito e da política e a ideia de Constituição (constitucionalismo moderno) responde atualmente como a estrutura que permitiu que os sistemas (do direito e da política) possam novamente se unir e manter-se separados (LUHMANN, 1990), para que possam evoluir.

A ideia de Constituição e a positivação de novos direitos advinda da complexidade atual trouxe, para o seio do sistema do direito, a noção de saúde, positivada como direito à saúde, e trouxe a noção de direito à saúde, positivada como saúde para o sistema da política, respectivamente, ou seja, a Constituição é responsável por fazer com que o sistema do direito suporte a positivação de valores e princípios e é responsável por fazer com que o sistema da política suporte a inclusão de direitos nos valores e princípios. Ambos os sistemas operam no que Maturana e Varela (2011) denominaram de ponto cego.

limites da comunidade, bem como determinar, mediante julgamentos ocasionais baseados nas circunstâncias atuais do fato, até onde os danos do exterior devem ser vingados; e em um e outro caso utilizar toda a força de todos os membros, quando houver necessidade. [...] juiz esse que é o legislativo ou os magistrados por ele nomeados. $E$, sempre que houver qualquer número de homens, associados embora, que não possuam tal poder decisivo para o qual apelar, estes ainda se encontrarão em estado de natureza" (LOCKE, 1991, p. 249-50).

${ }^{4}$ Todo sistema, como sistema parcial, tem que ser distinto internamente, tem que marcar uma unidade da diferença interna e externamente. Veja-se a seguinte passagem de Luhmann: "Tanto las reflexiones de la teoría de sistemas como las investigaciones empíricas sugieren la hipótesis de que el proceso de diferenciación de un sistema requiere del desarrollo simultáneo de una diferenciación interna" (LUHMANN, 2005, p. 359). 
Existindo a estrutura que permite a "reconexação" entre os sistemas do direito e da política, necessário compreender as mudanças estruturais que ocorreram no sistema do direito para que essa complexidade possa operacionalizar-se no atual contexto social brasileiro.

\section{A CONSTITUCIONALIZAÇÃO DOS DIREITOS SOCIAIS E A NECESSIDADE DE EXISTÊNCIA DE ESTRUTURAS OPERATIVAS PARA EFETIVAÇÃO DO DIREITO À SAÚDE}

No Brasil, a constitucionalização da saúde (como direito e como valor), quando da promulgação da Constituição de 1988, nos artigos 6o e 196, precipuamente, trouxe a tentativa de diminuição da complexidade por meio da noção, para o sistema do direito, de que a saúde agora era um direito de todos (LUHMANN, 2007, p. 47) e de que a saúde agora é uma política pública que deverá ser implementada para todos, ou seja, é um direito e é um valor ou princípio, simultaneamente, dependendo do ponto de vista que é observada a Constituição, ou melhor, dependendo de que sistema social a Constituição é observada.

A constitucionalização do direito à saúde trouxe como consequência, no âmbito do sistema do direito, a possibilidade de pessoas que, até então, eram ou estavam excluídas das políticas públicas governamentais a respeito da aquisição de medicamentos, intervenções cirúrgicas e outras necessidades vinculadas ao bem-estar (saúde) pudessem exigir do Poder Judiciário uma decisão que Ihes fosse favorável ou lhes garantisse o cumprimento do direito social positivado (direito à saúde), que se resume numa típica obrigação de fazer por parte dos gestores públicos.

O que antes da Constituição de 1988 era tratado como um valor ou princípio quando contido na Constituição e, portanto, não autoaplicável, é visto atualmente como um direito social constitucionalizado e, portanto, passível de ser exigido do Estado, seja por meio do sistema da política (tomada de decisões coletivamente vinculantes), seja por meio do sistema do direito (decisão judicial), não sendo mais possível, consequentemente, alegar a tese ventilada em Montesquieu a respeito da rígida separação de poderes.

A experiência de países com situação política semelhantes à do Brasil, como Portugal e Espanha, fizeram com que, no Brasil, se construísse a ideia de que seria possível a efetivação e o cumprimento da Constituição, no tocante aos novos direitos positivados, sendo o direito à saúde um deles, por meio de decisões judiciais, por meio do que se convencionou denominar de jurisdição constitucional (STRECK, 2002). A despeito da nomenclatura e eventuais discussões teóricas sobre o que seria "jurisdição constitucional", o certo é que se passou a acreditar que seria possível que o sistema do direito pudesse resolver, por meio da decisão de juízes, o cumprimento das "promessas" (direitos, valores e princípios) contidas na Constituição, dentre estas o direito à saúde.

Assistiu-se, no Brasil, o que se convencionou denominar de judicialização da saúde (VIANNA et al., 1999), ou seja, a enorme gama de excluídos da prestação de serviços de saúde por parte do Estado brasileiro (sistema da política), se dirigiu ao poder judiciário, por meio de ações patrocinadas pela Defensoria Pública, para exigir do Poder Executivo que Ihes fossem garantidos fármacos, intervenções cirúrgicas e outras demandas ou serviços vinculados à saúde (enquanto valor ou princípio) como forma de cumprimento do direito à saúde contido na Constituição de 1988.

Nesse momento - explosão de demandas judiciais e decisões proferidas pelos juízes (de primeiro grau), em relação ao cumprimento do direito à saúde (artigos 6 e 196, da Constituição) 
- convém observar o sistema do direito, ou melhor, auto-observar o sistema do direito no tocante à operacionalização do direito à saúde.

Essa observação poderá ser feita por meio da análise dos temas relativos ao instituto da repercussão geral. Os temas de números $234^{5}, 289^{6}$ e $542^{7}$ são um recorte neste momento suficiente para compreensão a respeito da inexistência de estruturas normativas no período anterior à emenda constitucional número 45/2004 e o consequente prejuízo à autopoiese do sistema do direito.

As questões jurídicas envolvidas no tocante ao cumprimento do direito à saúde contido na Constituição, anterior ao surgimento do instituto da repercussão geral, contidas nos temas 234, 289 e 542 são questões capazes de gerar uma procura dos excluídos por prestação jurisdicional no tocante à possibilidade de obtenção de um medicamento com custo elevado, ou de gerar um aumento expressivo no orçamento público em decorrência de sucessivos bloqueios judiciais nas contas públicas dos entes federados para compra de medicamentos ou para o reajuste da tabela de serviços do Sistema Único de Saúde (SUS), ou a possibilidade de extensão do benefício previdenciário de licença maternidade e aplicação da estabilidade provisória às gestantes contratadas temporariamente ou para cargos de confiança, com o consequente impacto financeiro para administração bem como para organização administrativa do órgão de lotação da gestante.

A operacionalização desse direito era feita pelo juiz de primeiro grau, pelo juiz lotado na comarca onde a ação foi ajuizada. Percebe-se, ajuizada a ação, que há ao menos duas ou mais possibilidades de julgamento (contingência), a complexidade do entorno obrigará que o juiz tome uma decisão, faça uma escolha para que seja possível diminuir a complexidade do entorno causada pela (dupla) contingência.

Poderia ocorrer que um juiz, fundamentando sua decisão por meio do código direito/não direito (sistema do direito), entendesse que a tabela de preços e valores dos serviços do SUS tivesse que ser reajustada pelo índice denominado IPC, outro pelo IGP-m e um terceiro juiz pelo INPC. Poderia ocorrer, igualmente, que um juiz de um Estado-membro do Brasil tomasse uma decisão, no seio do julgamento da ação, no sentido de que gestantes contratadas pelo regime temporário ou pelo regime de confiança (cargo em comissão) não teriam direito à estabilidade prevista na Constituição e não teriam direito à licença-maternidade. Por outro lado, existe a possibilidade de juízes lotados nas mais diversas comarcas dos Estados-membros do Brasil decidirem de maneira favorável às gestantes, no sentido de Ihes garantir o gozo de licença-maternidade e a estabilidade provisória prevista no Ato das Disposições Constitucionais Transitórias (ADCT).

\footnotetext{
${ }^{5}$ Tema 234: RE-602324: "Recurso extraordinário em que se discute, à luz dos artigos 2o; 5o, caput, XXXVI, LV, § 2o; 37, caput; 195, § 10우 197; e 199, § 1ํ, da Constituição Federal, o direito, ou não, ao reajuste das tabelas dos serviços hospitalares e ambulatoriais prestados ao Sistema Único de Saúde - SUS, em virtude das diferenças decorrentes da conversão monetária operada quando da implantação do Plano Real. (Direito Administrativo e Outras Matérias de Direito Público).

${ }^{6}$ Tema 289: RE-607582: "Recurso extraordinário em que se discute, à luz dos artigos 100, § 2o; e 167, II e VII, da Constituição Federal, a possibilidade, ou não, de bloqueio de verbas públicas para garantir o fornecimento de medicamentos." (Direito Administrativo e Outras Matérias de Direito Público).

${ }^{7}$ Tema 542: RE-842844: Recurso extraordinário com agravo em que se discute, à luz do artigo 20; do inciso XXX do art. 7o-; do caput e dos incisos II e IX do art. 37 da Constituição Federal, bem como da letra "b" do inciso II do art. 10 do Ato das Disposições Constitucionais Transitórias - ADCT, o direito, ou não, de gestante, contratada pela Administração Pública por prazo determinado ou ocupante de cargo em comissão demissível ad nutum, ao gozo de licença-maternidade e à estabilidade provisória, desde a confirmação da gravidez até cinco meses após o parto. (Direito Administrativo e Outras Matérias de Direito Público).
} 
As decisões tomadas pelos juízes, na sistemática anterior à emenda constitucional número 45/2004, era questionada por meio de recursos às instâncias superiores no tocante ao que se denominou chamar de controle difuso de constitucionalidade. Havia uma decisão prolatada pelo juiz (sentença), posteriormente, abria-se a possibilidade de recorrer a um tribunal que prolataria um acórdão e, depois dos tribunais de segundo grau, havia possibilidade de se recorrer ao Superior Tribunal de Justiça (STJ) ou ao Supremo Tribunal Federal (STF), ou a ambos.

O fato é que toda a decisão judicial aportava ao Supremo Tribunal Federal uma vez que inexistia qualquer tipo de "filtro" que permitisse que o STF previamente se manifestasse a respeito da possibilidade de admitir, ou não, o recurso extraordinário. A anterior sistemática permitia que o Supremo Tribunal Federal, mesmo já tendo decidido uma situação semelhante, fosse obrigado a decidir novamente sobre o mesmo assunto e assim sucessivamente, uma vez que o derrotado não encontrava limites na interposição de recursos no tocante à obrigatoriedade de conhecimento da matéria pelo STF.

A parte derrotada (em geral o Poder Público) tinha sempre a possibilidade de interposição de recurso de agravo de instrumento (atualmente, agravo) e, utilizando essa faculdade processual, obrigava o STF a conhecer da matéria. O Supremo Tribunal Federal, enquanto órgão de cúpula, era obrigado a conhecer todos os recursos, era obrigado a se manifestar a respeito da constitucionalidade, ou não, da interpretação dada pelas outras organizações pertencentes ao Poder Judiciário, ou seja, o STF não conseguia fazer e observar a diferença da unidade, não conseguia ser o órgão de cúpula (topo da pirâmide), ou, em termos sistêmicos, não conseguia ser a organização de centro ou central do sistema do direito.

A possibilidade de que fossem tomadas decisões, com base no código direito/não direito e todas fundamentadas no direito à saúde, previsto nos artigos 6 e 196, ambos da Constituição, fazia com que a autopoiese do sistema do direito ficasse comprometida ou prejudicada pelo fato de o sistema funcionar de maneira não racional e sem confiança.

Esse funcionamento não racional e sem confiança ocorria porque o sistema do direito não conseguia generalizar suas decisões (aplicação para futuras demandas semelhantes), isto porque a complexidade do entorno não era reduzida por meio de uma estrutura operacional capaz de retomar a confiança abalada do sistema do direito.

A ausência de confiança, como um conceito pertencente à teoria sistêmica, fez com que as decisões dos juízes não fossem consideradas aptas a ser generalizadas e aplicadas para demais ações com temas iguais ou semelhantes. Um sistema sem confiança é um sistema cuja autopoiese estará prejudicada, pois a possibilidade de existência de "uma decisão para cada caso" retira do sistema, além da confiança, a autorreferencialidade (LUHMANN, 1998, p. 395-396), elemento necessário, igualmente, para que a autopoiese seja mantida.

\section{INSTITUTO DA REPERCUSSÃO GERAL COMO ESTRUTURA OPERACIONAL QUE AUMENTA A CONFIANÇA DO SISTEMA DO DIREITO}

A confiança é um conceito da teoria sistêmica que responde de maneira eficaz (diminuição da complexidade) quando do aumento da complexidade da atual sociedade, uma vez que permite agir como um critério de antecipação de uma futura decisão. A função do sistema do direito é estabilizar as expectativas normativas, por meio de decisões (jurídicas), ou seja, o sistema do direito decide num determinado sentido e se decide num determinado sentido é porque poderia 
ter decidido de maneira diferente, ou seja, a contingência ${ }^{8}$ é um fator de risco. A confiança pode reconquisar a segurança jurídica que a dogmática tentou, porém não mais consegue atualmente.

Se o sistema do direito decide, é importante saber que possível decisão o sistema tomará, ou seja, a confiança traduz-se na antecipação do futuro, na previsibilidade de uma possível decisão futura no presente. A mudança de paradigma é notada sob o ponto de vista da decisão judicial, se antes era importante se voltar para o passado como passado e como um modelo decisório ${ }^{9}$ - dogmática jurídica - a modernidade não suporta esse paradigma, uma vez que não é possível, com base no passado ${ }^{10}$, diminuir a complexidade causada pelo risco da decisão contingente e, portanto, a confiança é um fator capaz de lidar de maneira mais eficaz com o futuro.

O futuro sempre comporta muito mais riscos que poderiam ser concretizados no presente, e a confiança ajuda a reduzir a complexidade na medida em que induz a uma tomada de decisão no presente, com base na confiança de que esta decisão repetir-se-á no futuro ${ }^{11}$. Em termos de mudança de paradigmas, é sintomático imaginar que o direito, enquanto sistema, estrutura-se não mais no passado, porém no futuro.

A confiança tem como característica aumentar a generalização das experiências (LUHMANN, 2005, p. 44), ou seja, estende a repetição da experiência a casos semelhantes, tendo como condão estabilizar a indiferença ante a variação. Para o sistema do direito, a confiança terá o condão de estabilizar as expectativas jurídicas com base em três características: deslocamento da problemática do 'externo' para o 'interno', um processo de aprendizagem e uma resolução simbólica dos resultados do entorno ${ }^{12}$.

No caso do julgamento dos temas ligados ao direito à saúde, toda certeza externa advinda do perigo criado pelo sistema da política é substituída pela certeza interna do sistema do direito em relação a uma possível decisão que repetirá outra decisão já tomada anteriormente ${ }^{13}$. Toda

\footnotetext{
${ }^{8}$ Convém lembrar que a base da teoria sistêmica diz respeito com a complexidade da atual sociedade. A complexidade gera necessidade de decisão, decisão é geradora de riscos e decidir é contingenciar, é escolher entre uma das possíveis possibilidades (LUHMANN, 2005, p. 9).

${ }^{9}$ Todo o passado é complexidade reduzida e por este motivo pouca valia tem para o futuro, na medida que não é possível aumentar-se a complexidade com base no passado. Eis a seguinte passagem: "El pasado no tiene otras posibilidades; éste es siempre complejidad ya reducida" (LUHMANN, 2005, p. 32).

${ }^{10}$ Para teoria sistêmica, o passado é sempre complexidade reduzida (LUHMANN, 2007, p. 698).

11 "Mostrar confianza es anticipar el futuro. Es comportarse como si el futuro fuera cierto. Uno podría decir que a través de la confianza, el tiempo se invalida o al menos se invalidan las diferencias de tiempo. Esto es quizá la base para la enseñaza de la moral que aparte del antegonismo oculto para con el tiempo, recomienda una actitud de confianza como un camino hacia la atemporalidad a través de la independencia del paso del tiempo" (LUHMANN, 2005, p. 15).

12 "Las decisiones acerca de la confianza generalizan experiencias, las extienden a otros casos similaers y estabilizan la indiferencia ante la variación, en la medida en que rinden satisfactoriamente la prueba. Este proceso de generalización de expectativas posee tres aspectos que son importantes y dignos de una consideración mayor: indica el desplazamiento parcial de la problemática de lo <externo> a lo <interno>, un proceso de aprendizaje y una resolución simbólica de los resultados en el entorno" (LUHMANN, 2005, p. 44).

${ }^{13}$ O Tema de número 793 (Recurso Extraordinário Constitucional e Administrativo. Direito à Saúde. Tratamento Médico. Responsabilidade Solidária dos Entes Federados. Reafirmação de Jurisprudência. Recurso Extraordinário Desprovido). O tratamento médico adequado aos necessitados se insere no rol dos deveres do Estado, sendo responsabilidade solidária dos entes federados, podendo figurar no polo passivo qualquer um deles em conjunto ou isoladamente. (Constitucional e Administrativo. Apelação Cível. Sistema Único de Saúde). Bem exemplifica a absorção do ruído, da irritação do sistema da política (perigo) pelo sistema do direito (risco). O sistema da política toma uma decisão coletivamente vinculante de não pagamento de um determinado tratamento médico com base na divisão interna de funções dos entes federados no tocante ao Sistema Único de Saúde. O sistema do direito processa o perigo (ruído) com o código direito/não-direito e decide que os entes federados são solidários no tocante
} 
complexidade externa, todo ruído é substituído pela certeza interna criada pelo próprio sistema. Essa certeza interna de que a confiança tem o condão de gerar no sistema ajuda à racionalidade deste, uma vez que ajuda a autopoiese do sistema do direito, no caso. A troca da certeza externa pela certeza interna por meio da confiança é a maneira como o sistema absorve o ruído, as irritações do entorno, processando-as por meio do código binário ${ }^{14}$.

Como processo de aprendizagem, a confiança desempenha papel importante, pois é, por meio da confiança, que será possível aprender e apreender o comportamento que deve ser tomado para que uma decisão tenha reflexos no futuro. O processo de aprendizagem para o sistema do direito é um processo que se desenvolve lentamente em suas organizações e tem como característica o fato de poder passar confiança não somente numa determinada operação, mas quando da realização de novas operações o processo de aprendizagem tentará outorgar confiança a novas decisões (LUHMANN, 2005, p. 47).

A confiança tem, como terceira característica, o condão de simbolizar o entorno, fixando o sentido de maneira a criar complexos simbólicos ${ }^{15}$ (LUHMANN, 2005, p. 48). É uma relação frágil que tende a se desestruturar com uma mentira ou um questionamento a respeito da veracidade da informação. O sistema do direito trabalha muito com esses complexos de símbolos para gerar confiança e diminuir a complexidade. Alusões ao significado de interesse público da administração, ao significado de bom pai de família e outras expressões dessa natureza ${ }^{16}$ remetem a uma fixação simbólica do sentido, e isso é necessário para que se possa decidir e diminuir a complexidade de que se tenha confiança de que inexistam dúvidas a respeito da conduta da pessoa envolvida, seja uma conduta de um bom pai de família ou que o administrador, ao decidir, visou ao melhor para o interesse público da administração.

A confiança como uma das maneiras de se visualizar a evolução do sistema do direito mostra que a segurança jurídica atualmente não poderá ser buscada com base no passado e, portanto, a dogmática jurídica perde muito de sua importância. Em se tratando de decisões envolvendo direito à saúde, é importante observar que a confiança será necessária a fim de se conseguir repetir decisões jurídicas no presente com intuito de estabilizar o futuro. Se o paradigma anterior fazia com que o passado se insinuasse no futuro, o paradigma atual faz com que o futuro se insinue no presente.

ao pagamento de despesas relativas a tratamento médico, transformando doravante em risco - dano contingenciável - eventual expectativa das partes na obtenção de decisões judiciais que confirmem a decisão já tomada por meio do julgamento da repercussão geral relativa ao Tema 793. O risco é transferido ao sistema do direito que deverá se vincular às suas próprias decisões.

${ }^{14}$ As expectativas cognitivas e as expectativas jurídicas precisam de confiança de que as decisões tomadas no presente serão tomadas no futuro, ou seja, precisam confiar que é possível contingenciar o futuro por meio de decisões no presente, tornando a certeza do entorno uma certeza do sistema. "El caso de la confianza, la redución de la complejidad adopta formas especiales a causa de su naturaleza subjetiva. Tales formas pueden describirse como cambios en el nivel em que se absorbe, o se hace tolerable, la incertidumbre. El sistema sustituye la certeza externa por la certeza interna, y al hacerlo eleva la tolerancia de la incertidumbre en las relaciones externas. Debido a esto el problema de como reducir la complejidad, relativo a su presencia en el entorno, es cambiado para ser parte de los problemas secundarios de esta certeza interna" (LUHMANN, 2005, p. 45).

15 "Las personas y las disposiciones sociales en las que uno pone la confianza, se convierten en complejos de símbolos que son especialmente sensibles al disturbio y que por decirlo así, registran cada suceso en términos del problema de la confianza".

${ }^{16}$ Para Viehweg (2008, p. 21-46), seria o resgate da tópica aristotélica, abandonada na aurora do Iluminismo e resgatada atualmente. No mesmo sentido, Sousa Santos ao trabalhar com a retórica da decisão judicial (SOUSA SANTOS, 1988, p. 17-29). 
Outra importante contribuição da retomada de estruturas aptas à operacionalização da confiança no sistema do direito é o resgate do papel do Supremo Tribunal Federal em relação à organização do sistema do direito. Luhmann (2007a) propõe que se trabalhe com a noção de centro e periferia ao invés da noção hierárquica advinda da tradição. Para Luhmann (2007a), a hierarquia é uma das maneiras com que as organizações se distribuem, porém, atualmente, deve-se observar que a dicotomia centro/periferia consegue responder pela diminuição da complexidade de maneira sistêmica.

\section{INSTITUTO DA REPERCUSSÃO GERAL COMO RESGATE DA CENTRALIDADE NO SISTEMA DO DIREITO PELO SUPREMO TRIBUNAL FEDERAL}

Trabalhar com a noção centro/periferia ${ }^{17}$ contida na teoria sistêmica é admitir que a complexidade oriunda da atual contingência poderá ser reduzida por meio de organizações que exerçam o papel central no sistemas, no caso do sistema do direito, o Supremo Tribunal Federal seria a organização central, e todas as demais organizações terão que se vincular ao tribunal para que a autopoiese do sistema do direito seja mantida.

A centralidade é resgatada porque, na sistemática anterior à mudança legislativa relativa ao instituto da repercussão geral (Emenda Constitucional número 45/2004), os juízes (de primeiro grau) poderiam julgar as demandas com base no texto constitucional sem qualquer tipo de vinculação com alguma decisão anterior proferida pelo Supremo Tribunal Federal, poderiam, inclusive, julgar de maneira que sequer precisariam observar as decisões anteriores tomadas por outros juízes.

Igualmente, os tribunais de segundo grau poderiam julgar as demandas com base no direito à saúde sem haver a estrita necessidade de se vincularem as decisões já tomadas pelo tribunal em casos semelhantes, ou seja, tanto as decisões proferidas pelos juízes (sentenças) como as decisões proferidas pelos tribunais de segundo grau (acórdãos) não eram passíveis de generalização, não geravam confiança e ainda abordavam questões relativas a valores ou princípios, uma vez que decidiam apenas com base no texto constitucional positivado.

Segundo a teoria sistêmica, há necessidade de existência de um órgão (enquanto organização) central ou centralizador, capaz de dissipar ou capaz de trabalhar e omitir os paradoxos existentes entre os sistemas quando estão acoplados estruturalmente.

Existindo na Constituição, conforme já trabalhado no início deste trabalho, positivação de direitos e positivação de valores e princípios, forçoso concluir que se abre, paradoxalmente, para o sistema do direito a possibilidade de se trabalhar com valores e princípios e para o sistema da política com direitos, todavia ambos os sistemas não podem compreender que estão trabalhando com códigos diversos, pois haveria o risco de comprometer a autopoiese desses mesmos sistemas.

Como resolver essa equação no âmbito da teoria sistêmica: organização central ou centralizadora capaz de operar no ponto cego, no paradoxo, sem contudo causar estranhamento. Nesse contexto, o Supremo Tribunal Federal é o órgão de cúpula, o órgão de centro e o órgão (entendido como organização) capaz de operar com os direitos e valores positivados na Constituição sem, contudo, causar estranhamento para o sistema da política e para o sistema do direito.

\footnotetext{
${ }^{17}$ Os tribunais, no caso as cortes constitucionais ou os tribunais que ocupam esta função, são considerados centro do sistema do direito (LUHMANN, 2005, p. 359-399).
} 
De nada adiantava a existência da menção na Constituição de 1988 ao STF como órgão de cúpula, como órgão centralizador (organização, para teoria sistêmica) se não havia estrutura que permitisse que o STF exercesse esse poder. Atualmente, o instituto da repercussão geral permite que o Supremo Tribunal Federal autorreferencie-se, se auto-observe e decida a respeito de processos ligados à aplicação do direito à saúde, como os temas já elencados (Temas 234, 289 e 542), e esta decisão, além de ser obrigatória para os membros da própria organização, será obrigatória para as demais organizações do Poder Judiciário. Caso haja descumprimento por parte das organizações periféricas, há estruturas que garantem a operacionalização das decisões do STF, impondo sempre uma garantia de que o futuro está sempre se insinuando no presente.

O instituto da repercussão geral permite que o Supremo Tribunal Federal possa selecionar, previamente, que processos irá julgar, que processos são dignos de ser julgados pela corte. Agora é possível que o STF selecione uma causa dentre tantas que estão tramitando no seio do Poder Judiciário e, com base numa decisão, evita-se que diversas outras ações idênticas ou semelhantes sejam rejulgadas pelo Supremo Tribunal Federal. A resposta não deixa de ser interessante e deve ser analisada como uma evolução do sistema do direito para que não ocorresse a perda da racionalidade e para que não tivesse - o sistema do direito - a todo momento, repetir (por meio do controle difuso quando do julgamento pelo STF de recurso extraordinário) as mesmas decisões já tomadas anteriormente, o que faria com que o sistema do direito tivesse a confiança ${ }^{18}$ abalada. Confiança reconquistada pelo sistema do direito ao se auto-observar, uma vez que as diversas decisões judiciais no tocante ao direito à saúde e as possibilidades de mudança das decisões pelos tribunais locais contribuíam apenas para que pudesse ocorrer frustração no tocante à estabilização das expectativas jurídicas. Em sendo o Supremo Tribunal Federal organização considerada central do sistema do direito, nada mais natural que fosse encarregada dessa estabilização das decisões, propiciando ao sistema do direito que possa autorreferenciar-se por meio de suas próprias decisões.

A generalização na aplicação da mesma decisão em casos idênticos ou muito assemelhados resgata a confiança e devolve o papel centralizador do Supremo Tribunal Federal, papel este que lhe possibilita efetivar o direito à saúde.

\section{EFETIVAÇÃO DO DIREITO À SAÚDE POR MEIO DE DECISÕES DO SUPREMO TRIBUNAL FEDERAL}

Se a Constituição é a solução artificial que permite que o direito observe o sistema da política, e a política observe o sistema do direito e faça com que as decisões jurídicas possam remeter-se a questões políticas e, mesmo assim, continuarem jurídicas e vice-versa, é importante observar como essa operação acontece, como esse paradoxo ocorre e como o sistema (do direito e da política) não consegue visualizar o acoplamento estrutural- ponto cego - entre os sistemas.

\footnotetext{
${ }^{18}$ Já foi abordado a respeito da necessidade de um sistema ser e ter confiança. Não é possível que para cada decisão já tomada sobre os mesmos assuntos o sistema do direito tenha que se repetir de maneira exaustiva e até mesmo abundante. A repetição, a tautologia é uma característica dos sistemas sociais, porém ela não pode ser exagerada, sob pena de perda de confiança e racionalidade (LUHMANN, 2005).
} 
Esse ponto cego, esse acoplamento estrutural responde por Constituição, operacionalizando-se por meio de conceitos indeterminados ${ }^{19}$. Observados os Temas de número $262^{20}$ (discute-se a legitimação do Ministério Público em ajuizar ação civil pública para compelir o Estado de Minas Gerais a entregar medicamentos a portadores de hipotireoidismo e hipocalcemia), $289^{21}$ (discute-se a possibilidade de bloqueio de verbas públicas para garantir o fornecimento de medicamentos) e $312^{22}$ (discute-se a possibilidade de o Poder Judiciário realizar interpretação extensiva no tocante aos critérios de concessão de benefício assistencial), do instituto da repercussão geral ${ }^{23}$, percebe-se que a própria Constituição permite que o juiz tome decisões cujos fundamentos reportem-se a códigos de outros sistemas e, mesmo assim, a decisão continua sendo entendida pelo sistema do direito como uma decisão jurídica. Os conceitos indeterminados possuem valores e princípios obrigando o administrador a fornecer saúde por meio de políticas, e gastos públicos para aquisição de medicamentos é que permitem que os juízes façam ilações, façam referências alopoiéticas, façam referências a princípios e valores e, mesmo assim, as decisões continuem sendo consideradas como jurídicas, uma vez que estão baseadas na Constituição, as decisões são fundamentadas nos artigos da Constituição.

Por outro lado, os mesmos conceitos indeterminados existentes na Constituição no sentido de fornecer saúde, de realizar políticas sociais e econômicas que visem à diminuição de doenças, é o que permite ao Administrador, na pessoa do Presidente da República, do Governador de Estado, do Prefeito ou de algum Ministro ou Secretário, tomar decisões de realizar uma vacinação em massa em relação a algum tipo de doença ou um vasto programa de medicação para pessoas soropositivas, e essas ações serão consideradas decisões políticas, mesmo que a referência seja à Constituição e aos conceitos indeterminados.

É nesse espírito que se deve compreender a função do Supremo Tribunal Federal, como organização central do sistema do direito: efetivação do direito à saúde.

A efetivação do direito à saúde ocorrerá quando do julgamento dos temas vinculados à operacionalização do referido direito à saúde, isto porque a decisão do STF terá o condão de participar de dois sistemas jurídicos simultaneamente. Para o sistema do direito, para as organizações periféricas (juízes, tribunais de segundo grau, Ordem dos Advogados do Brasil, Ministério Público, Defensoria Pública entre outras), a decisão proferida pelo Supremo Tribunal Federal em relação aos temas apontados neste artigo serão decisões jurídicas, mesmo que os fundamentos da decisão reportem-se a valores ou princípios. Para o sistema da política, a decisão tomada pelo STF em relação aos mesmos temas será considerada uma decisão coletivamente vinculante e

\footnotetext{
${ }^{19}$ Embora exista vasta literatura a respeito, as definições e conceitos são retirados do pensamento de Engish (2004).

${ }^{20}$ Tema 262: RE-605533: "Recurso extraordinário em que se discute, à luz artigos 20; 127; 129, II e III; 196; e 197, da Constituição Federal, a legitimidade, ou não, do Ministério Público para ajuizar ação civil pública que visa compelir o Estado de Minas Gerais a entregar medicamentos a portadores de hipotireoidismo e hipocalcemia. (Direito Processual Civil e do Trabalho).

${ }^{21}$ Tema 289: RE-607582: "Recurso extraordinário em que se discute, à luz dos artigos 100, § 2o-; e 167, II e VII, da Constituição Federal, a possibilidade, ou não, de bloqueio de verbas públicas para garantir o fornecimento de medicamentos." (Direito Administrativo e Outras Matérias de Direito Público).

22 Tema 312: RE-580963: "Recurso extraordinário em que se discute, à luz do art. 203, V, da Constituição Federal, a constitucionalidade, ou não, de decisão judicial que, conferindo interpretação extensiva ao parágrafo único do art. 34 da Lei n. 10.741/2003, deixa de computar benefício assistencial concedido a pessoa com deficiência ou qualquer outra situação não contemplada expressamente no referido dispositivo do Estatuto do Idoso, para fins do cálculo da renda familiar de que trata o art. 20, §3ำ, da Lei n. 8.742/93. (Direito Previdenciário).

${ }^{23}$ Emenda Constitucional n. 45/2004.
} 
fará com que o sistema da política absorva esse risco por meio do código (fechamento operativo) que lhe é peculiar: governo/oposição.

Percebe-se que as decisões do Supremo Tribunal Federal participam ou têm a possibilidade de participar de dois sistemas simultaneamente sem, contudo, causar estranhamento, isto porque cada um dos sistemas absorve as decisões do STF de maneira a manter hígida a autopoiese do sistema do direito (decisão jurídica tomada com base no código direito/não direito) e do sistema da política (decisão política tomada com base no código governo/oposição) e ambos os sistemas continuam operando de maneira independente, embora acoplados estruturalmente pela Constituição.

Atualmente, esta é a mudança estrutural que ocorreu no sistema do direito para que se pudesse efetivar o direito à saúde.

\section{CONCLUSÃO}

A teoria sistêmica, de matriz luhmaniana, permitiu a observação da complexidade da atual sociedade e como essa complexidade foi absorvida pelo sistema do direito por meio de mudanças em sua estrutura.

A positivação do direito à saúde na Constitiução de 1988 trouxe como consequência a necessidade do sistema da política tomar decisões coletivamente vinculantes que pudessem ofertar esse serviço público à totalidade da população e fez com que o sistema do direito necessariamente tivesse de decidir, quando acionado por meio de ação, pela aplicação do referido direito à saúde ao jurisdicionado.

Ocorre que, em países como o Brasil, de baixa operacionalidade do sistema da política (política simbólica), o Poder Executivo que deveria investir no cumprimento da Constituição no tocante à oferta de serviços públicos vinculados à saúde a toda população, omitiu-se, fazendo com que o fenômeno conhecido como judicialização da política ou judicialização da saúde se tornasse uma das formas de também efetivar o direito à saúde.

A crença de que o Poder Judiciário poderia "fazer política" por meio de decisões judiciais não se evidenciou ao longo dos anos posteriores à promulgação da Constituição de 1988. O que se viu foi o sistema do direito alterando suas estruturas para que pudesse manter sua autopoiese e, assim, evoluir.

A possibilidade dada aos juízes de primeiro grau e aos tribunais de apelação de proferirem decisões judiciais com fundamento no direito à saúde contido na Constituição (artigos 6으 e 196, precipuamente) mostrou que o sistema do direito, inicialmente, não conseguiu absorver a complexidade do entorno que Ihe garantisse a higidez de sua autopoiese. Essa complexidade não era absorvida porque as decisões judiciais não eram passíveis de generalização porque elas - decisões judiciais- não continham, sob o enfoque sistêmico, confiança.

O sistema do direito não conseguiu (e não conseguia) emprestar confiança às suas decisões e, não emprestando confiança nas decisões tomadas pelos juízes e tribunais, era um sistema cuja racionalidade estava comprometida, na medida em que cada ação ajuizada por um cidadão poderia gerar uma decisão diferente quando se tratasse a respeito de fornecimento de algum fármaco, por exemplo. O sistema do direito não conseguia contingenciar o futuro, não conseguia diminuir o risco de decisões conflitantes ou divergentes porque a estrutura existente não emprestava confiança às decisões judiciais dos juízes e tribunais. 
Foi necessário que o sistema do direito se auto-observasse para que pudesse criar estruturas - mudança - capaz de absorver a complexidade do entorno, capaz de reduzi-la num primeiro momento e capaz de dotar confiança de que seria possível decidir da mesma maneira em casos semelhantes.

O instituto da repercussão geral no atual momento histórico de "judicialização da política" ou "judicialização da saúde" foi a mudança estrutural que permitiu a evolução do sistema do direito no tocante à operacionalização da Constituição como aquisição evolutiva. O instituto da repercussão geral garantiu que o sistema do direito operacionalizasse o Supremo Tribunal Federal como organização centralizadora, permitiu que o fechamento operativo e a abertura cognitiva proporcionada pela Constituição se revelassem e se apagassem, mantendo o paradoxo de o sistema do direito suportar decisões proferidas pelo STF contendo valores e princípios, e que essas decisões sirvam de referência (generalização) a todas as demais organizações (periféricas) do sistema do direito para que possam gerar a necessária confiança na jurisdição constitucional.

\section{REFERÊNCIAS}

ENGISH, Karl. Introdução ao pensamento jurídico. Lisboa: Fundação Calouste Gulbenkian, 2004.

LOCKE, John. Segundo tratado sobre o governo. São Paulo: Nova Cultural, 1991.

LUHMANN, Niklas. La sociedad de la sociedad. Mexico: Herder, 2007a. . Teoría política en el estado de bienestar. Madrid: Alianza Universidad, 2007b. . Confianza. Barcelona: Anthropos, 2005a.

El derecho de la sociedad. Mexico: Herder, 2005b. . Sistemas sociales: lienamentos para uma teoria general. Barcelona: Anthropos, 1998. . Verfassung als evolutionäre Errungnschaft. Rechhistorisches Journal, n. 9, 1990.

MATURANA, Humberto; VARELA, Francisco. A árvore do conhecimento: as bases biológicas da compreensão humana. São Paulo: Palas Athena, 2011.

MONTESQUIEU. Do espírito das leis. São Paulo: Nova Cultural, 1997.

SOUSA SANTOS, Boaventura de. O discurso e o poder: ensaio sobre a sociologia da retórica jurídica. Porto Alegre: Fabris, 1988.

STRECK, Lenio Luiz. Jurisdição constitucional e hermenêutica: uma nova crítica do direito. Porto Alegre: Livraria do Advogado, 2002.

VIANNA, Luiz Werneck et al. A judicialização da política e das relações sociais no Brasil. Rio de Janeiro: Revan, 1999.

VIEHWEG, Theodor. Tópica e jurisprudência: uma contribuição à investigação dos fundamentos jurídicocientíficos. Porto Alegre: Fabris, 2008.

\section{Sobre os autores:}

Sandra Regina Martini: Possui graduação em Ciências Sociais pela Universidade do Vale do Rio dos Sinos (1983), mestrado em Educação pela Pontifícia Universidade Católica do Rio Grande do Sul (1997), doutorado em Evoluzione dei Sistemi Giuridici e Nuovi Diritti pela Università Degli Studi di Lecce (2001), Pós-doutorado em Direito (Roma Tre, 2006) e pós-doutorado em Políticas Públicas (Universidade de Salerno, 2010). Foi professora titular da Universidade do Vale do Rio 
dos Sinos, da Scuola Dottorale Internazionale Tullio Ascarelli e professora visitante da Universita Degli Studi Di Salerno. Foi diretora da Escola de Saúde Pública do Rio Grande do Sul (janeiro de 2007 a fevereiro de 2011), foi membro (de janeiro de 2008 a dezembro de 2013) do Conselho Superior da Fundação de Amparo à Pesquisa do Estado do Rio Grande do Sul (FAPERGS). Atualmente é Pesquisadora Produtividade 2 CNPq, professora do Centro Universitário Ritter dos Reis (Uniritter), professora visitante no programa de pós-graduação em Direito da UFRGS (PPGD). É avaliadora do Basis do Ministério da Educação e Cultura e do Basis do Instituto Nacional de Estudos e Pesquisas Educacionais Anísio Teixeira. Parecerista ad hoc CNPq e CAPES. Conferencista no Brasil e no exterior. Tem experiência na área de Direito, com ênfase em sociologia jurídica, atuando principalmente nos seguintes temas: saúde pública, políticas públicas, sociologia jurídica e sociedade e direitos humanos. E-mail: srmartini@terra.com.br

André Santos Chaves: Doutor e Mestre em Direito pela UNISINOS. Procurador do Município de Porto Alegre. Diretor Cultural da Associação dos Procuradores do Município de Porto Alegre (APMPA). Vice-Diretor da Fundação Escola Superior de Direito Municipal (ESDM). Sócio fundador de Chaves, Rudnicki \& Pinto Advogados Associados. E-mail: oabrs42907@terra.com.br 
